\title{
Culturally Embedded Mechanism, Guanxi in Marketing
}

\author{
Meiling Wong1, Ping-Chieh Huang2 \\ ${ }^{1}$ National Taiwan Chinyi University of Technology, Taichung, Taiwan \\ ${ }^{2}$ Suzhou University, Taipei, Taiwan \\ Email: mlwong001@gmail.com
}

Received 18 June 2015; accepted 7 July 2015; published 14 July 2015

\begin{abstract}
While it is emphasized in Western on "what you know", which refers to technological expertise, including the price and quality of tendered product or service, it is emphasized in Confucian societies on "who you know", which refers to personal connections with the appropriate authorities or individuals. These connections are known in Chinese as guanxi. The present paper attempts to explore the underlying mechanism of guanxi which is culturally embedded onto added value of service quality by examining the construct equivalence of the two concepts between Western relationship marketing and Chinese guanxi. This paper provides an inner view of cultural value which offers insights that should prove helpful to academics in management and related disciplines as well as to practitioners engaged in Chinese business.
\end{abstract}

\section{Keywords}

\section{China, Guanxi, Relationship Marketing}

\section{Introduction}

In contrast to transactional marketing, relationship marketing focuses more on establishing, developing and maintaining successful relational exchanges and good customer relationship [1]. In relational exchange, the choice behavior is constrained through the trust and commitment that develop between the two parties [2]. Parallel to this shift in the marketing paradigm, there is a growing research interest in guanxi, which has been considered as the Chinese version of relationship marketing or business networking [3]-[6]. Although some relationship marketing principles are regarded as a key determinant for a successful business in China, the uniqueness of Chinese culture makes the direct transfer of Western relationship marketing principles into China or other Asian societies questionable [6]. As a general result, studies conducted in one country may not be generalizable to others because of national culture effects. This is essentially a question of external validity and research should be encouraged to determine which marketing principles can be universally applied and which are basically ethnocentric [7].

The present paper attempts to explore the underlying mechanism of guanxi which is culturally embedded and its effect on added value of service quality. It firstly discusses the unique meaning of wulune, which is proposed 
as an underlying mechanism of guanxi that guides behavior norms in Chinese society and thus affects the business. And an empirical study is constructed with an empirical study to verify the propositions. Finally, it concludes by discussing the managerial implications for international marketers who wish to succeed in the Chinese business market and the importance of adapting Western relationship marketing principles to guanxi marketing.

\section{Wulune in Guanxi}

With respect to social context, Chinese culture provides a tightly knitted social framework in which individuals are protective of one another and organizations safeguard their members' interests. The importance of networks lies in their emphasis on collectivism and group harmony. For each specific relationship, people in China 'reconcile' through interpersonal accommodation and negotiation [8]. In China, guanxi has been a way of life since time immemorial, thus the personal investment required to develop and maintain good social relations is accepted as an unavoidable fact of life. Guanxi projects a preference for cooperation, group decision-making, and relationships. The Chinese strive to keep relationships among guanxi members stable and harmonious since guanxi is the basis on which they exchange a lifetime of favors, resources, and business leverage [9].

Social norms, though somewhat are different around the world, mostly are attached to the social status, which is the position where people stand in a social system. And the regulation integrated for a certain status is the "role" [10]. Chinese social status is determined largely by guanxi system to which one belongs-a determination often preordained by the composite membership of one's extended family. For someone who takes the proper role and plays it accordingly receives high praise for being qualified for his social status [6]. Guanxi interaction has been viewed by many scholars as an idiosyncratic cultural phenomenon in Chinese society [11] where Confucianism is the major life philosophy. Wulune, the basic norms of guanxi, is the main thought of the ideal type of manhood and patriarchy and filial piety and the spirit of trust and justice in regulating different levels of guanxi and setting them in hierarchical order with priorities in Chinese societies. It consists of five levels: the monarch and his subjects, the father and his son, brothers, friends, and the husband and his wife. In this guanxi system, while the three basic guanxi of the father and his son, brothers, and the husband and his wife are inside of the family, the political guanxi of monarch and his subjects is up-pushed to the national level, and guanxi of friends contains the rest of those who are outside of the families. From the perspective of Chinese societal progress, the "family-nation-world" is the structure from inside out where the family ethic is the basis of Confucius' human relations, where each one ought to be committed, responsible, and content to his given role. As long as every member in the group follows the rules, the whole society stays in harmony.

Guanxi is characterized into categories in accordance with its bases [12] [13]. No matter how guanxi is classified and implemented theoretically, in practice there are certain rules for each role played among parties in accordance with wulune. And rules are often borrowed when guanxi cannot be clearly defined in between two parties. For example, in a business relationship where no blood-ties exists, one often intentionally effort on building guanxi as brothers, friends, or other kinds of relationship in wulune to share the privileges and have resource and favor exchanged. China is a society built based upon Confucianism where people are tied closely into varieties of guanxi, whose networks bind millions of Chinese firms into social and business webs, largely dictating their success [9] [14]. While guanxi sets the interpersonal "protocol" with rules governing the communication and transferring affection between individuals in Chinese societies, the teaching of Confucianism culturally rooted, wulune in effect constructs the norms of guanxi for its establishment and maintenance.

As Hwang (1987) characterized guanxi bases, the strongest ones are referred to as the affective or "expressive" ties found among family members and close friends [12]. In contrast, more distant others, such as salesmen and customers, connected by temporary "instrumental" ties that are enacted regularly in the pursuit of material goals unless there is a "metaphor" relationship built in (as discussed in above section). In between the two extremes are found "mixed" ties, which are governed by norms of equality and thus describe the most active domain for guanxi networking. For these mixed ties, guanxi is more like a network of relationships a person cultivates through the exchange of gifts and favors to attain mutual benefits. It is based on friendship and affection, and on a reciprocal obligation to respond to requests for assistance. In markets, people see one invisible hand-price, while in Chinese business, another hand-guanxi is seen as a potential solution for most problems of entering and operating in China.

From a sociological view, in Fei's research, guanxi is based upon chaxugeju [15], with which measures the relationship between oneself and others and decides where they stand in the guanxi chuen (circle). Chinese in- 
ter-personal relationships is described as ripples caused by a stone thrown into the water circled along the core, which is based upon oneself surrounded by all others (See Figure 1). Following along the ripples, the farther others position, the farther the relationship one has with them. This phenomenon of Chaxugeju explains the relationship differentiation of guanxi. It is the basic principle of social structure in the Chinese society, in comparison with Western societies, there is differentiation among relationships in accordance with the level of closeness, relatedness, and social classes, etc.

Yang (2002) has described guanxi building as the transformation process whereby two discrete individuals construct a basis of familiarity to enable the subsequent development of relationship [16]. And in this process, the gap between two hitherto unrelated individuals is bridged so that an outsider becomes part of the inside social circle of another person [17]. Take locality as an example for further elaboration. Locality is one of the common forms of ascribed guanxi bases in China to the group identification, where Da-ton-hsiang refers to members from the same province, and Hisao-ton-hsiang refers to a even closer relationship for members from the same village. People from the same origin have the affection for their hometown, this kind of liking thus is passed down to each other, which ties them together and reinforces their friendliness.

\section{Guanxi in Business}

While the role of guanxi has been well analyzed, guanxi and business strategy have not yet been properly integrated into the theoretical concept that links the relevant elements of both organizations.

The individual "similarities" make it easier for interpersonal connection and interaction, especially for individual's intention on joining another guanxi chuen. For instance, $A$ is one of the members of $Z_{1}$ group while $B$ is one of the members of $Z_{2}$ group; and $A$ has the intention on joining the $Z_{2}$ group to get acquainted with $C$ who is able to assist his business. Therefore A starts to look for "guanxi link" he needs to link him up to $Z_{2}$. He figures $\mathrm{B}$, a classmate from his collegiate belonged to $\mathrm{Z}_{2}$ group may be a help. So he contacts $\mathrm{B}$ and asks for a reunion to refresh their classmate ship. The more frequent they meet, the closer their relationship gets. Later on more than just being classmates by now, $\mathrm{A}$ and $\mathrm{B}$ have formed up their own guanxi chuen $\mathrm{Z}_{3}$. They get along like brothers and care for each other like a family. Furthermore whatever is related to B now is also related to A as shown in Figure 2. The role-context prescribed for their relationship is brotherhood, and they are expected to fulfill the obligations attached to the role playing. Either one disobey the rules will receive disrespectfulness not just from the other one, but the whole society since the role-context is the social norm of conduct with cultural constraint.

Guanxi chuens link up like this and it goes on and on until all the related similarities are utilized and all possible chuens are connected. $A s Z_{5}$ and $Z_{3}$ are linked up and turned into a bigger chuen as shown in Figure 3 .

Within this kind of guanxi business, reliability, assurance, responsiveness, and trust are natural intrinsic based upon the guanxi built in between the parties, and promise or accuracy is expected to tag along with the role defined with their guanxi, which is to be committed instead of being required. In business, firms sell mostly similar products and services except the sales persons' attitude, which is what really counts in making deals with their customers. Tangibles thus are considered less inconsequential to customers than how they are being treated. And

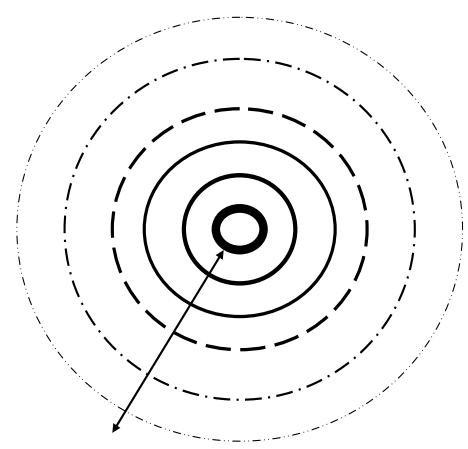

差序格局

Figure 1. Chaxugeju. 


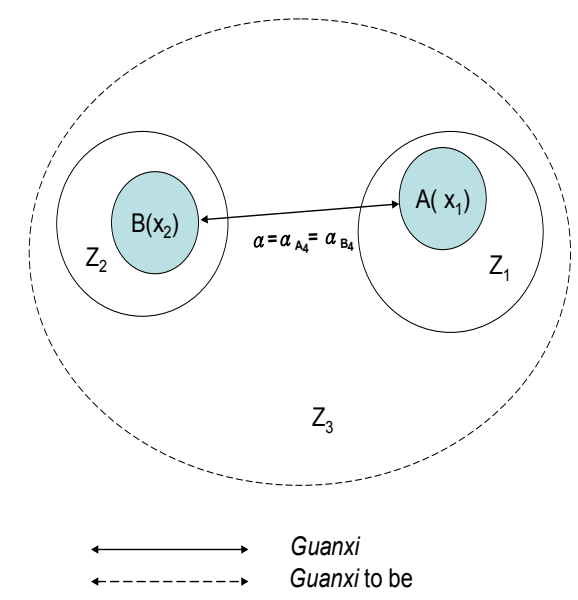

Figure 2. The ISOLINK network development I.

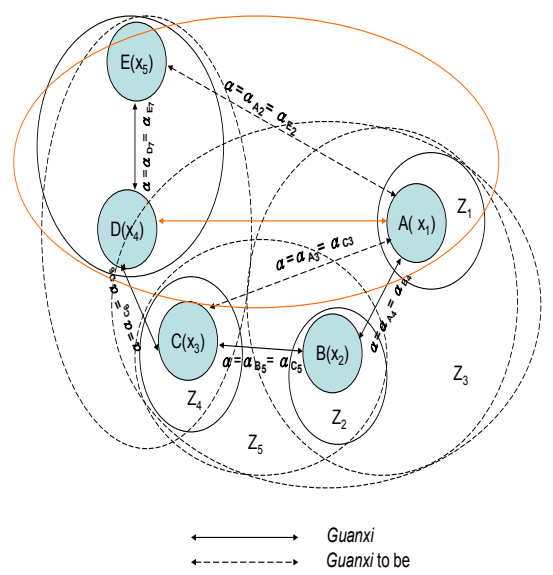

Figure 3. The ISOLINK network development of Guanxi circles.

empathy is expected as a two-way treatment for both sides (service provider and receiver). A good guanxi reinforces relationship marketing and ensures its success whereas a bad guanxi spoil relationship marketing and in turn terminates the transaction.

\section{Managerial Implication}

Relationship marketing may be effective in achieving transactional sales; it faces more challenges in maintaining the long lasting customer relationship with royalty, which demands tremendous resource invested. Guanxi in a way also requires "investment", in a sense of putting effort to the "heart-to-heart" communication to reassure that the mutual belief in each other's role in playing along with its obligation always exists and remains as they expect. It takes attention and care, which are time and energy consuming. In addition to that, it is noted that guanxi is able to "inherit" or "transfer, which is another interesting subject for further research.

Although the purpose of this paper was to analyze culturally embedded mechanism of guanxi in marketing, we realize that there are likely to be other associations not specially examined in this paper that warrant future attention. There are a few suggestions for future research. First, wulune, on the basis of Confucianism in effect defining the social roles and classifying their hierarchical system, is in fact the cornerstone for guanxi construct. The effect of the teaching of Confucianism is dynamic which may vary with the possibility of generation gap. How guanxi mechanism works for next generation in recognizing and manipulating with their guanxi networks deserves more attention and studies. Second, since guanxi is the essential element of social link, its value context and mechanism require further research. 


\section{References}

[1] Berry, L.L. and Parasuraman, A. (1991) Marketing Services: Competing through Quality. The Free Press, NY.

[2] Morgan, R.M. and Hunt, S.D. (1994) The Commitment-Trust Theory of Relationship Marketing. Journal of Marketing, 58, 20-38. http://dx.doi.org/10.2307/1252308

[3] Amber, T. (1994) Marketing's Third Paradigm: Guanxi. Business Strategy Review, 5, 69-80. http://dx.doi.org/10.1111/j.1467-8616.1994.tb00084.x

[4] Davies, H., Leung, T.K.P., Luk, S.T.K. and Wong, Y. (1995) The Benefits of "Guanxi”. Industrial Marketing Management, 24, 207-214. http://dx.doi.org/10.1016/0019-8501(94)00079-C

[5] Lovett, S., Simmons, L.C. and Kali, R. (1999) Guanxi versus the Market: Ethics and Efficiency. Journal of International Business Studies, 30, 231-247. http://dx.doi.org/10.1057/palgrave.jibs.8490068

[6] Wang, C.L. (2007) Guanxi vs. Relationship Marketing: Exploring Underlying Differences. Industrial Marketing Management, 36, 81-86. http://dx.doi.org/10.1016/j.indmarman.2005.08.002

[7] Cunningham, W.H. and Green, R.T. (1984) From the Editor. Journal of Marketing, 48, 9-10.

[8] Imrie, B.C., Cadogan, J.W. and McNaughton, R. (2002) The Service Quality Construct on a Global Stage. Managing Service Quality, 12, 10-18. http://dx.doi.org/10.1108/09604520210415353

[9] Pearce II, J.A. and Robinson, R.B. (2000) Cultivating Guanxi as a Foreign Investor Strategy. Business Horizons, 3138. http://dx.doi.org/10.1016/S0007-6813(00)87385-1

[10] Chang, T.S. (1986) Social Theory. Giu Liu, Taipei, 239-240.

[11] Lee, M.Y. and Ellis, P. (2000) Insider-Outsider Perspectives of Guanxi. Business Horizons, 25-30.

[12] Hwang, K.-K. (1987). Face and Favor: Then Chinese Power Game. American Journal of Sociology, 92, $944-974$. http://dx.doi.org/10.1086/228588

[13] Nuang, D.T. (1992) Contemporary Human Relationship and Interaction. LongJian Social Science, 6, 64-67.

[14] Gibb, A. and Li, J. (2003) Organizing for Enterprise in China: What Can We Learn from the Chinese Micro, Small, and Medium Enterprise Development Experience. Future, 35, 403-421. http://dx.doi.org/10.1016/S0016-3287(02)00089-7

[15] Fei, X.T. (1992) From the Soil: The Foundations of Chinese Society (Transl. by Hamilton, G.G. and Wang, Z.). University of California Press, Berkeley, CA.

[16] Yang, M.M. (1994) Gifts, Favors, Banquets: The Art of Social Relationship in China. Cornell University Press Ithaca, NY.

[17] Yeung, I.Y.M. and Tung, R. (1996) Achieving Business Success in Confucian Societies: The Importance of Guanxi (Connections). Organizational Dynamics, 54-65. http://dx.doi.org/10.1016/S0090-2616(96)90025-X 